\title{
Meningkatkan Peran Perempuan melalui Pengarusutamaan Gender di Kecamatan Cibatu Kabupaten Purwakarta
}

\section{Eti Jumiati}

Program Studi Perbankan Syariah STAI Al-Muhajirin Purwakarta, Indonesia, 41117

E-mail: etijumiati425@gmail.com

DOI: https://doi.org/10.37339/jurpikat.v1i2.272

\section{Info Artikel: \\ Diterima : \\ 2020-08-28 \\ Diperbaiki : \\ 2020-09-10 \\ Disetujui : \\ 2020-10-24}

Kata kunci: Gender, PUG, PPRG

\begin{abstract}
Abstrak: Kegiatan pengabdian masyarakat yang dilaksanakan di Kecamatan Cibatu Kabupaten Purwakarta berfokus pada masalah "peran perempuan di masyarakat".Sampai saat ini masih banyak masyarakat khususnya di Kecamatan Cibatu Kabupaten Purwakarta, yang bias gender. Gagal paham tentang gender dapat mengakibatkan ketidakadilan gender. Tujuan dari pengabdian kepada masyarakat ini adalah: 1) Memberikan pemahaman kepada masyarakat tentang Pengarusutamaan Gender (PUG); 2) Memberikan pemahaman tentang Kesetaraan dan Keadilan Gender (KKG); 3) Memberikan pemahaman tentang isu-isu gender yang terjadi di masyarakat; 4) Strategi pemberdayaan masyarakat dalam meningkatkan peran perempuan di masyarakat. Metode yang dilakukan dengan memberikan sosialisasi terhadap masyarakat di Kecamatan Cibatu. Sebelumnya dilakukan riset guna memperoleh data terpilah terkait peran perempuan dan isu gender di Kecamatan Cibatu. Hasil pengabdian kepada masyarakat adalah pemahaman tentang peran, fungsi, tanggungjawab, sikap dan perilaku perempuan dan laki-laki dalam meningkatkan taraf hidupnya di masyarakat.
\end{abstract}

Abstract: Community service activities carried out in Cibatu Subdistrict, Purwakarta Regency, focus on the 
Keywords: Gender, PUG, $P P R G$ problem of "the role of women in society". Until now, there are still many people, especially in Cibatu District, who are gender biased. Failure to understand gender can lead to gender inequality. The objectives of community service are: 1) Providing understanding to the community about Gender Mainstreaming; 2) Provide an understanding of Gender Equality and Justice; 3) Provide an understanding of gender issues that occur in society; 4) Community empowerment strategies in increasing the role of women in society. The method was providing socialization to the community in Cibatu District. Research was conducted to obtain data related to the role of women and gender issues in Cibatu District. The result of community service is an understanding of the roles, functions, responsibilities, attitudes and behavior of women and men in improving their standard of living in society.

\section{Pendahuluan}

Perempuan dan laki-laki berbeda, baik secara biologis maupun secara konstruksi social budaya. Dari perbedaan tersebut akan melahirkan kebutuhan yang berbeda pula antara keduanya. Perbedaan laki-laki dan perempuan secara biologis disebut jenis kelamin. Jenis kelamin merupakan ciptaan Allah yang tidak bisa berubah dan berlaku sepanjang zaman. Sedangkan perbedaan laki-laki dan peremuan secara konstruksi social budaya disebut dengan Gender. Jadi Gender adalah perbedaan peran, fungsi, tanggungjawab, sikap dan perilaku antara laki-laki dan perempuan hasil konstruksi social budaya, yang dapat dipertukarkan dan berubah sesuai dangan kondisi dan situasi dimana laki-laki dan perempuan itu tinggal.

Contoh ketidakadilan gender di masyarakat yang sampai saat ini masih terjadi diantaranya: marjinalisasi, beban ganda (double burden), kekerasan berbasis gender (gender based violence). Marjinalisasi atau pemiskinan adalah suatu proses peminggiran akibat perbedaan jenis kelamin yang mengakibatkan kemiskinan.

Asumsi bahwa peran perempuan sebagai pekerja domestik, ketika bekerja di sector public seringkali dianggap sebagai fungsi perempuan sebagai pencari nafkah tambahan. Dari pandangan tersebut proses marjinalisasi berlangsung hingga sekarang. Peran perempuan di sector public berada pada tempat-tempat yang berpenghasilan rendah, seperti pekerja konveksi, buruh pabrik, asisten rumah tangga dan sebagainya. Di Kecamatan Cibatu sudah banyak perusahaan-perusahaan atau industri-industri yang pekerjanya sebagian besar perempuan. Sangat jarang 
perempuan menjadi seorang sebagai pengambil keputusan ataupun duduk di organisasi dan sejajar dengan laki-laki.

Beban Ganda (double burden) adalah beban pekerjaan yang lebih banyak dilakulan oleh jenis kelamin tertentu. Pada kenyataannya diskriminasi ini lebih banyak dibebankan kepada perempuan pekerja sebagai buruh. Perempuan yang bekerja dobel yakni bekerja di wilayah public juga harus bekerja di wilayah domestik secara tidak seimbang. Pembagian peran yang tidak adil ini sering diplesetkan dengan wilayah reproduksinya sebagai kodrat. Peran sangat berbeda dengan kodrat. Kodrat perempuan adalah segala sesuatu yang tidak bisa dipertukarkan dengan lakilaki seperti menstruasi, hamil, melahirkan dan menyusui. Sedangkan peran seperti mengasuh anak dapat dilakukan baik oleh laki-laki maupun perempuan.

Kekerasan berbasis gender (Gender based violence) merupakan ketidak adilan gender yang masih sering terjadi. Kekerasan Berbasis Gender (Gender Based Violence) merupakan konsep yang sering disebut dengan istilah konsep payung (umbrella term) dari berbagai tindakan yang membahayakan fisik, seksual dan psikologi (The International Federation of Red Cross and Red Crescent Socient-IFRC, 2016), yang dilakukan dengan paksaan berdasarkan perbedaan gender antara laki-laki dan perempuan (Inter-Agency Standing Committee-UNDP, 2008).

Dampak dari kekerasan berbasis gender lebih banyak dirasakan oleh perempuan daripada oleh laki-laki. Meskipun kekerasan berbasis gender ini dapat menimpa anak laki-laki. Kasus kekerasan di desa lebih banyak disebabkan oleh factor ekonomi. Contohnya kekerasan dalam rumah tangga (KDRT) merupakan manisfestasi dari ketimpangan gender (gender gap) dan korbannya adalah perempuan.

Perempuan selalu merasa tak berdaya dan terkesan pasrah. Budaya patriaki yang sudah turun temurun dan merupakan sebuah tradisi yang menjadikan perempuan selalu berada pada posisi yang tidak diuntungkan. Sikap diam perempuan dan tidak berani melaporkan kejadian kekerasan tersebut merupakan manifestasi dari budaya patriaki tersebut.

Indikator kesetaraan dan keadilan gender dapat ditunjukkan oleh Kualitas sumber daya manusia yang meningkat dan peran perempuan yang baik, atau dapat dilihat dari Indeks pembangunan manusia (IPM) maupun indeks pembangunan gender (IGD).

Indeks pembangunan manusia Provinsi Jawa Barat di kabupaten/kota, Purwakarta ada pada posisi ke 14 (empat belas) dari 27 (dua puluh tujuh) Kabupaten Kota. Ini menunjukkan bahwa IPM Kabupaten Purwakarta masih rendah. Dari data tersebut diperoleh IMP perempuan lebih rendah dibanidngkan laki-laki. (BPS Jawa 
Barat, 2019). Indeks Pembangunan Manusia (IPM) Menurut Kabupaten Kota dan Jenis Kelamin disajikan pada tabel 1.

Tabel 1. Indeks Pembangunan Manusia (IPM) Menurut Kabupaten Kota dan Jenis Kelamin

\begin{tabular}{ccc}
\hline \multirow{2}{*}{$\begin{array}{c}\text { Wilayah Jawa } \\
\text { Barat }\end{array}$} & \multicolumn{2}{c}{$\begin{array}{c}\text { Indeks Pembangunan Manusia (IPM) Menurut Kabupaten } \\
\text { Kota dan Jenis Kelamin }\end{array}$} \\
\cline { 2 - 3 } & Laki-laki & Perempuan \\
\cline { 2 - 3 } & $\mathbf{2 0 1 9}$ & $\mathbf{2 0 1 9}$ \\
\hline Subang & 72.5 & 65.68 \\
Purwakarta & 75.64 & 65.64 \\
Karawang & 74.41 & 67.31 \\
Bekasi & 78.98 & 69.94 \\
Kota Banjar & 76.64 & 66.77 \\
\hline
\end{tabular}

Sumber: BPS Jawa Barat

Sedangkan indicator indeks pembangunan manusia di kabupaten Purwakarta, di tahun 2018 pertumbuhan menurun, dapat ditunjukkan pada Tabel 2 di bawah ini:

Tabel 2. Indeks Pembangunan Manusia Tahunan

\begin{tabular}{|c|c|c|c|c|c|c|c|c|}
\hline \multirow{2}{*}{ Komponen IPM } & \multicolumn{8}{|c|}{ Indeks Pembangunan Manusia Tahunan } \\
\hline & 2011 & 2012 & 2013 & 2014 & 2015 & 2016 & 2017 & 2018 \\
\hline $\begin{array}{l}\text { Angka Harapan } \\
\text { Hidup }(\mathrm{AHH})\end{array}$ & 69.9 & 69.93 & 69.95 & 69.96 & 70.26 & 70.34 & 70.42 & 70.61 \\
\hline $\begin{array}{l}\text { Harapan Lama } \\
\text { Sekolah (HLS) }\end{array}$ & 10.26 & 10.71 & 11.22 & 11.33 & 11.44 & 11.82 & 11.89 & 12.09 \\
\hline $\begin{array}{l}\text { Rata-rata Lama } \\
\text { Sekolah (RLS) }\end{array}$ & 7.04 & 7.07 & 7.11 & 7.17 & 7.35 & 7.42 & 7.74 & 7.75 \\
\hline $\begin{array}{l}\text { Pengeluaran } \\
\text { (Komponen IPM) } \\
\text { (Rp. 000) }\end{array}$ & 10111 & 10333 & 10492 & 10521 & 10550 & 10732 & 10941 & 11372 \\
\hline $\begin{array}{l}\text { Indeks } \\
\text { Pembangunan } \\
\text { Manusia }\end{array}$ & 65.51 & 66.3 & 67.09 & 67.32 & 67.84 & 68.56 & 69.28 & 69.98 \\
\hline Pertumbuhan IPM & - & 1.21 & 1.19 & 0.34 & 0.77 & 1.06 & 1.05 & 1.01 \\
\hline
\end{tabular}

Dari uraian tersebut di atas dapat disimpulkan bahwa Pemahaman terhadap gender masih rendah, yang menyebabkan ketidaksetaraan dan ketidakadilan gender terhadap perempuan masih tinggi, hal tersebut dapat dibuktikan dengan pertumbuhan indeks pembangunan manusia tidak stabil. Indeks pembangunan manusia akan meningkat ketika indeks pembangunan gendernya juga meningkat. 


\section{Metode}

Berdasarkan latar belakang tersebut di atas, penulis bersama tim perencanaan dan penganggaran responsif gender Dinas Pemberdayaan dan Perlindungan Anak melakukan pemberdayaan masyarakat dengan penjelasan sebagai berikut:

Waktu pelaksanaan : 2 Mei 2019

Lokasi Pengabdian : Kecamatan Cibatu Kabupaten Purwakarta

Metode

: Pemberdayaan perempuan melalui PUG, Sosialisasi dengan metode ceramah, diskusi dan bermain peran tentang gender. Pemberian informasi tentang kesehatan, public, layanan reproduksi, tempat pengaduan dan sebagainya. Penjelasan metode Gender Analysis Pathway (GAP) dan Gender Budgeting Statement, berdasarkan data pilah, kebijakan, program dan kegiatan yang sudah dan belum direncanakan.

Strategi : Percepatan PUG melalui Perencanaan, Penganggaran Responsif Gender.

Tahapan pelaksanaan pemberdayaan perempuan di Desa Cibatu disajikan pada Gambar 1.

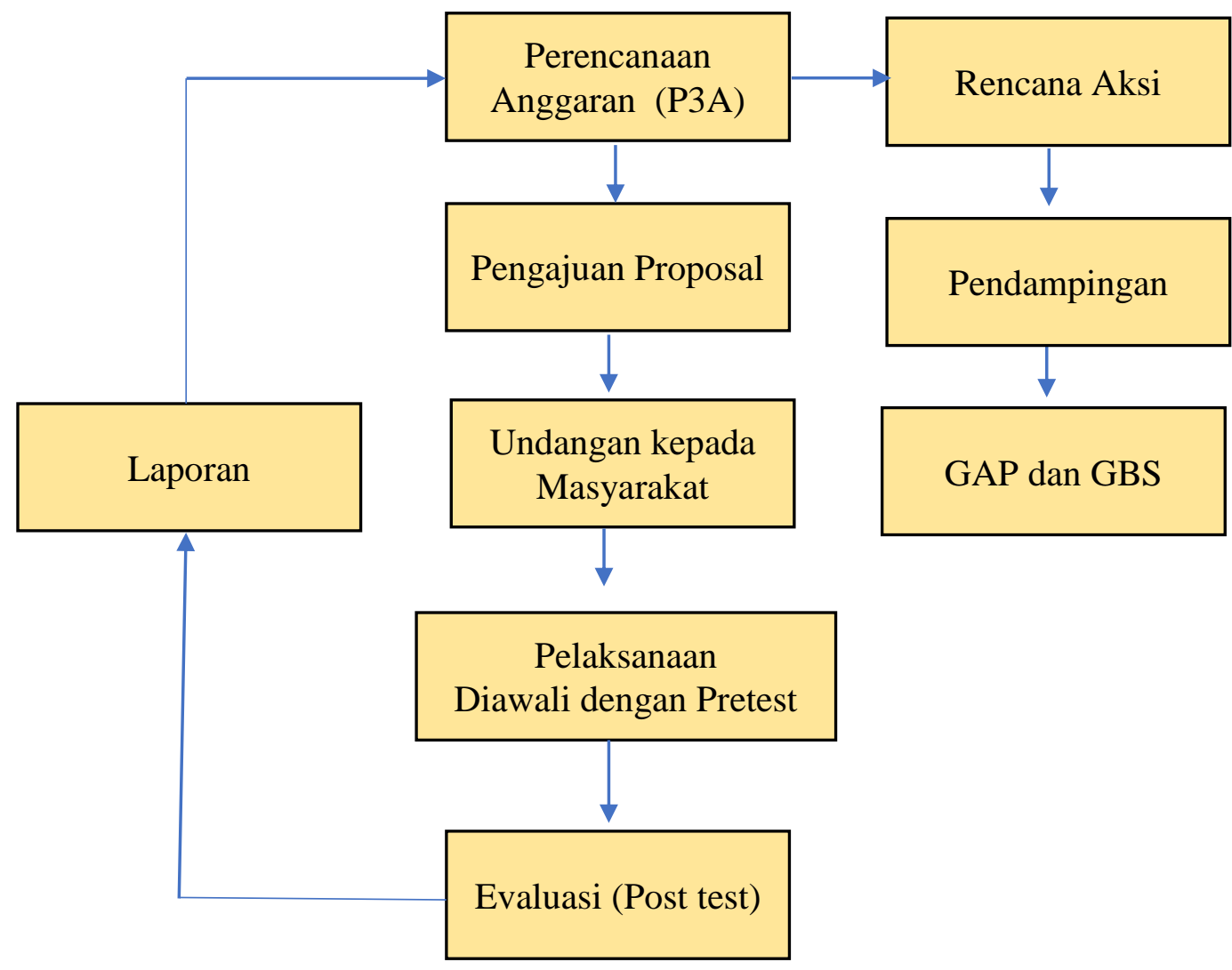

Gambar 1. Alur kegiatan 


\section{Hasil dan Pembahasan}

Berdasarkan Instruksi Presiden No. 9 tahun 2000, tentang Pengarusutamaan Gender, bahwa PUG adalah strategi yang dibangun untuk mengintegrasikan gender menjadi satu dimensi integral dari perencanaan, penyusunan, pelaksanaan, pemantauan, dan evaluasi atas kebijakan dan program pembangunan nasional. Jadi PUG adalah strategi, bukan program.

Strategi pengabdian pada masyarakat Kecamatan Cibatu sebagai berikut:

1. Pelaskanaan PUG

PUG dilaksanakan di Kecamatan Cibatu, melalui pemberian pemahaman tentang gender, isu gender, kesetaraan dan keadilan gender dengan memberikan contohcontoh dan yang akurat. Indikator PUG adalah meningkatnya kesetaraan dan keadialn gender (KKG). Terwujudnya kesetaraan dan keadilan gender ditandai dengan tidak adanya diskriminasi antara laki-laki dan perempuan dalam memperoleh Akses, Partisipasi, Kontrol dan Manfaat (APKM) terhadap pembangunan. Kegiatan sosialisasi PUG disajikan pada Gambar 2.

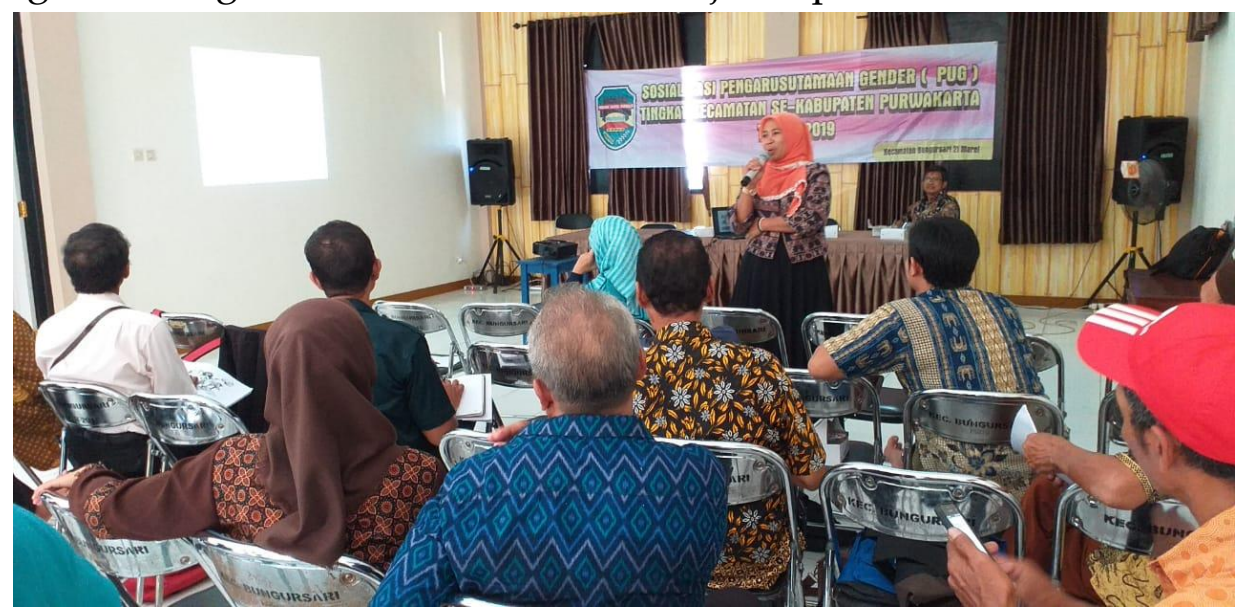

Gambar 2. Kegiatan Sosialisasi

2. Perencanaan Penganggaran Responsif Gender (PPRG)

Agar upaya pembangunan dapat merespon kebutuhan laki-laki dan perempuan maka isu gender (suatu kondisi yang menunjukkan adanya kesenjangan/gap antara laki-laki dan perempuan) harus terintegrasi ke dalam program pembangun desa melalui kecamatan. Karena itu perlu dibentuk SDM yang paham gender dan mampu menjadi aktivits gender dengan dibentuk kelompok kerja. Kelompok kerja ini kemudian di latih agar mampu menganalisis gender, dan merencanakan kebijakan /program/kegiatan kedalam instrument yang mampu mengakomodir pembangunan yang responsive gender yaitu Gender Analysis Pathway (GAP) dan Gender Budgeting Statemen (GBS). Hasil kegaitan peran pemberdayaan perempuan melalui PUG disajikan pada Tabel 3. 
Tabel 3. Hasil kegiatan peran pemberdayaan melalui PUG

\begin{tabular}{llccc}
\hline No & Desa/Kecamatan & Kehadiran & $\begin{array}{c}\text { Pemahaman } \\
\text { Gender (pre test) }\end{array}$ & $\begin{array}{c}\text { Pemahaman } \\
\text { Gender (pos test) }\end{array}$ \\
\hline 1 & Desa Cibungur & 6 & 0 & 6 \\
2 & Desa Wanakerta & 5 & 0 & 4 \\
3 & Desa Karangmukti & 4 & 0 & 4 \\
4 & Desa Dangdeur & 4 & 0 & 4 \\
5 & Desa Ciwangi & 4 & 0 & 3 \\
6 & Desa Cinangka & 6 & 0 & 5 \\
7 & Desa Cikopo & 5 & 0 & 5 \\
8 & Desa Cibodas & 4 & 0 & 4 \\
9 & Desa Cibening & 8 & 0 & 6 \\
10 & Desa Bungursari & 3 & 0 & 3 \\
11 & Kec. Cibatu & 12 & 0 & 11 \\
\hline
\end{tabular}

\section{Kesimpulan}

Dari hasil kegiatan sosialisasi PUG masayarakat di kecamatan Cibatu saat ini sudah memahami peran, fungsi, tanggung jawab, sikap dan perilaku perempuan dan laki-laki yang bermanfaat bagi masyarakat. Diharapkan kesetaraan dan keadilan gender dapat meningkat dan turunnya diskriminasi terhadap gender (baik laki-laki dan perempuan). Pembangunan yang responsive gender sudah sebagian dilaksanakan. Seperti ruang laktasi, sekolah TK di Desa, Peningkatan pemeriksaan kesehatan anak dan perempuan, Kamar mandi yang responsive gender, dan pembagian peran di dalam keluarga, keberanian perempuan untuk berani maju menjadi bagian dari pembangunan di Desa.

\section{Ucapan Terima Kasih}

Kesuksesan pengabdian kepada masyarakat di Kecamatan Cibatu Kabupaten Purwakarta ini tidak lepas dari peran pihak-pihak yang terkait. Untuk itu saya mengucapkan terima kasih kepada:

1. Dinas Pemberdayaan Perempuan dan Perlindungan Anak (P3A) Dinas Sosial yang bersedia melakukan pendampingan.

2. Semua Kepala Desa Kecamatan Cibatu yang telah care mengirimkan persertanya dari Desa masing-masing

3. Camat dan Staff Kecamatan Cibatu, yang telah bersedian menyiapkan tempat, saran dan prasarananya serta melibatkan semua staff di Kecamatan Cibatu. 
4. Masyarakat di kecamatan Cibatu yang telah bersedia berubah menuju kearah yang lebih baik.

5. Dan pihak-pihak lain yang tak sempat saya sebutkan dalam laporan pengabdian pada masyarakat ini

\section{Referensi}

Kementerian Pemberdayaan Perempuan dan Perlindungan Anak. Glosary KetidakadilanGender.https://www.kemenpppa.go.id/index.php/page/view/23 BPSKabupaten Purwakarta. 2019. https://purwakartakab.bps.go.id/subject/26/indekspembangunan-manusia.html

Instruksi Presiden. Nomor 9 tahun 2000 tentang Pengarusutamaan Gender (PUG). https://www.bappenas.go.id/files/8613/5229/8462/inpresno9th2000_20120409 103627_3504_1.pdf

IFRC 2016 World Disasters Rport, Resilience: Saving lives today, investing for tomorrow, RFRC, Geneva. Technical Report, October 2016

Humanitarian Coordinators Pol Mapping Exercise. Report for the Inter Agency Standing Committee. Oktober 2008.

BPS Jawa Barat, 2019. Jawa Barat dalam Angka. https://jabar.bps.go.id/publication/2019/08/16/b0a6b953b76cbe2239dc912d/pro vinsi-jawa-barat-dalam-angka-2019.html

Instruksi Presiden No. 9 tahun 2000. Pengarusutamaan Gender Dalam Pembangunan Nasional

P3A. Dinas Sosial. 2018. Pedoman Sosialisasi Pengarusutamaan Gender terhadap Masyarakat Purwakarta.

Ismi Dwi Astuti. AustraliaAid. Indonesia Australia Partnership for Desentralitation (AIPD). Jakarta

BPS Kabupaten Purwakarta. Kecamatan Cibatu dalam Angka. 2019. https://purwakartakab.bps.go.id/publication/2019/09/26/fdb92c07e5db013991c f1620/kecamatan-cibatu-dalam-angka-2019.html 